\title{
Research on the Training Strategies of Adult Learners' English Self-Efficacy
}

\author{
Ruihong Huang \\ Teaching Center, Zhejiang Open University, Hangzhou, China \\ Email: 870534247@qq.com
}

How to cite this paper: Huang, R. H. (2020). Research on the Training Strategies of Adult Learners' English Self-Efficacy. Open Journal of Social Sciences, 8, 25-34. https://doi.org/10.4236/jss.2020.85003

Received: April 10, 2020

Accepted: May 6, 2020

Published: May 9, 2020

Copyright $\odot 2020$ by author(s) and Scientific Research Publishing Inc. This work is licensed under the Creative Commons Attribution International License (CC BY 4.0).

http://creativecommons.org/licenses/by/4.0/

\begin{abstract}
Self-efficacy is one of the important theories of learning motivation. English self-efficacy is a person's self-evaluation of his English ability, which shows his confidence in English application. Its influencing factors include success or failure experience, alternative experience, verbal persuasion, physiological and emotional state, etc. As adult learners lack self-confidence and self-awareness in English learning, the study on the training strategies of adults' English self-efficacy plays a positive role in improving adults' English learning abilities and learning interests.
\end{abstract}

\section{Keywords}

Adult Learners, English Self-Efficacy, Training Strategies, Influencing Factors

\section{Introduction}

With the deepening of education reform, the guiding ideology of people-oriented quality education has been put into practice in education. The cognitive factors represented by intelligence and the traditional teaching mode dominated by knowledge accumulation have not been able to meet the requirements of the new era. It has become an irreversible trend to attach importance to the main role of students in education and the cultivation of students' non intelligence factors. In the structure of non intelligence factors, learning motivation is the core and the important prerequisite and foundation for students to achieve success. As an important intermediary factor in the process of achievement motivation, self-efficacy is an important link and direct factor affecting students' learning effect and achievement (Bandura, 1977). Self-efficacy determines how people feel, think, motivate and behave.

English is one of the important language tools to acquire knowledge and information. In recent years, with the continuous application of English in all 
walks of life, the demand for English is higher and higher in China. For adult learners, it is particularly important to improve their English learning ability. Because adult learners have many unfavorable factors in English learning, such as the past experience and experience of English learning failure, the decline of mechanical memory ability with the growth of age, therefore, the study of adult English self-efficacy and the cultivation of adult English self-efficacy play a positive role in promoting adult learners' English learning ability and interest, which is of great significance for adult learners to learn English.

\section{The Connotation of Self-Efficacy and English Self-Efficacy}

\subsection{The Theory of Self-Efficacy}

Self-efficacy was first proposed by Albert Bandura, the great master of contemporary social learning theory, in 1977. Then in 1986, Bandura comprehensively and systematically discussed the mechanism of self-efficacy, making it an important part of Bandura's social learning theory system.

Bandura's self-efficacy is one of the important theories of learning motivation. Since the 1980s, this theory has been enriched and developed, and supported by a large number of empirical studies. The research of many scholars at home and abroad shows that learners' self-efficacy improvement has a very important impact on their academic progress (Zhang et al., 2017). In the theory of self-efficacy, Bandura points out that human behavior is influenced by the outcome factor and antecedent factor of behavior and the outcome factor of behavior is reinforcement. The emergence of behavior is not due to the subsequent reinforcement, but to the expectation of the next reinforcement after people understand the dependency relationship between behavior and reinforcement. His expectation concept is different from the traditional expectation concept. The traditional expectation concept only refers to the expectation of the result, and he believes that there is a kind of efficacy expectation besides the expectation of the result. Efficacy expectation refers to people's speculation or judgment on whether they can carry out a certain behavior, that is, people's speculation on their own behavior ability. When a person is convinced that he has the ability to carry out an activity, he will have excessive self-efficacy. After acquiring the corresponding knowledge and skills, self-efficacy becomes the decisive factor (Bandura, 1995).

J. W. Atkinson also believes that learners' motivation determines the time allocation in different behaviors, and the degree of motivation in a certain behavior has a linear positive correlation with the time spent in the behavior (Atkinson \& Feather, 1980). In short, the level of learners' self-efficacy will affect the distribution of their psychological resources in the learning process and the effect of learning. It can be seen that people with high self-efficacy will achieve more success if they show proper self-confidence in their activities. However, people with low self-efficacy show low self-confidence, which affects their normal ability and reduces their probability of success. 


\subsection{The Connotation of English Self-Efficacy}

The theory of self-efficacy has a profound influence in the field of educational psychology, especially in language teaching and learning. The affective factors in language learning cannot be ignored. English self-efficacy is a person's self-evaluation of his English ability, which shows his confidence in English application, that is, people's self-evaluation of whether they can complete the ability of English language application. It is the embodiment of self-efficacy in English application. It is actually a specific application of self-efficacy theory in the process of English learning practice. It is not about a person's ability to learn English in the past, but to judge what he will learn in the future. In other words, English self-efficacy is not a description of an individual's ability to use English, but a perceptual judgment of his own self-efficacy ability.

Many studies show that self-efficacy affects people's work performance. People with high self-efficacy are better than people with low self-efficacy in persistence and final performance (Pajares, 1996). Self-efficacy can predict the speed of problem solving and the effect of skill learning, including the result of language learning (Bandura, 1977). Meiying Zhang's (2006) research on college students shows that self-efficacy of learning ability is positively correlated with self-efficacy of development ability, two factors of academic self-efficacy are positively correlated with motivation to pursue success and negatively correlated with motivation to avoid failure. Liping Chi and Ziqiang Xin (2006) found that the higher the sense of efficacy, the higher the endogenous motivation, but it has nothing to do with exogenous motivation. Hang Li (2017) pointed out that students' writing self-efficacy is an important variable, which can directly affect students' writing performance. The higher the students' self-efficacy, the higher their writing achievement. Therefore, to improve adult learners' self-efficacy is the key to improve their English learning ability.

\section{Factors Influencing English Self-Efficacy}

Bandura (1986) thinks that the development of self-efficacy is influenced by four factors: one is the past achievement experience, the other is alternative experience, the third is verbal persuasion, the fourth is physiological and emotional state. Self-efficacy affects people's thinking, feeling, motivation mode and individual's choice of activities. It also affects individual's choice of goals, effort, and persistence in the face of difficulties, and then affects their achievements and performance. English self-efficacy is also mainly affected by these four factors.

\subsection{Success or Failure Experience in Learning English}

The past achievement experience has the greatest impact on self-efficacy. The success or failure experience of English learning refers to the information or direct experience obtained through practice. The individual mainly obtains the knowledge about his own ability through his own experience. Because it is the most reliable knowledge about oneself gained by one's own experience, it be- 
comes the most powerful information source of self-efficacy. Successful English learning experience will improve students' English self-efficacy; on the contrary, repeated failure of English learning experience will reduce students' English self-efficacy. Continuous success will make students build up a stable sense of self-efficacy. This sense of self-efficacy will not be reduced due to temporary mistakes, and repeated failures will weaken the sense of self-efficacy. And this kind of situation will even be generalized to similar situations. If students have established a high sense of self-efficacy through multiple successes, then occasional failure will not have much impact on their sense of self-efficacy.

\subsection{Alternative Experience}

One aspect of self-efficacy is the alternative experience that individuals gain through observing the demonstration of role models. Learning from others' experience is an important source of individual self-efficacy. People often compare themselves under the same conditions with specific people, such as classmates, colleagues, opponents or people who work the same in other environments. When adults see that students with a similar level of ability have achieved success in English learning, they will enhance their sense of self-efficacy and think that they can achieve the same results; on the contrary, they will reduce their sense of self-efficacy and feel that they will not have the hope of success.

\subsection{Verbal Persuasion}

In many cases, individuals do not evaluate their abilities on their own. To some extent, people's self-evaluation is based on the viewpoint of "authority". Verbal persuasion includes persuasive suggestion, implication, evaluation and advice. This information usually comes from the encouragement of English teachers, parents, classmates and authoritative idols. When others affirm their English learning ability, they may be more confident, put in more efforts to complete the task and stick to it, or try to do things they didn't dare to do before. In particular, it should be pointed out that this kind of verbal persuasion is more effective when one lacks independent and objective judgment on the current abilities and difficulties. What we should pay attention to is, the first is that the effect of verbal persuasion depends on the degree of trust and reputation of the persuader, the second is that speech persuasion without factual basis has little effect on the formation of self-efficacy.

\subsection{Physiological and Emotional State}

People's physiological condition, stress level and emotion will affect their self-efficacy. To some extent, people's ability to judge themselves depends on the change of physiological and emotional state. Self-efficacy indirectly influences English learning by controlling non-intelligence factors. And non-intelligence factors refer to the emotion, individual interest, motivation and effort related to learning. Individuals with high self-efficacy have strong learning motivation and 
will try their best to achieve their goals. They can face setbacks optimistically and are not prone to anxiety. On the contrary, the students with low self-efficacy have self doubt and give up halfway when they encounter difficulties, which leads to anxiety.

\section{Characteristics of Adult Learners' English Learning}

With the further demand of the society for adult continuing education, more and more adults enter the classroom for further education after taking part in the work. Their enthusiasm for English learning is very high, but the learning effect is not obvious. There are many factors that cause this situation, such as students' weak English foundation, unsatisfactory teaching conditions and environment, etc., and low self-efficacy is the key factor that causes their learning difficulties. The characteristics of adult learners' English learning are as follows.

\subsection{Adult Learners' Lack of Successful Experience in English Learning}

People with strong sense of self-efficacy tend to attribute failure to lack of effort or unfavorable environment, while those who think they are inefficient think that failure comes from low self-ability. Because of the long-term experience of failure in English learning, adult learners often do not objectively analyze the difficulty of the task and the degree of effort paid for it, but simply misunderstand or exaggerate the difficulties in English learning. Due to their obstacles in English learning, they often have incorrect attribution styles, tend to attribute their failure in learning to internal stable factors, such as low intelligence and poor ability, and attribute their occasional success to external factors such as good luck, easy tasks and help from others. This negative way of attribution makes them seldom experience the sense of achievement and satisfaction in learning, lose confidence in their ability to learn English, doubt that their efforts will produce good results, so they often give up their efforts in English learning and take a negative attitude.

\subsection{Adult Learners' Anxiety in English Learning Process}

Generally speaking, adult learners are more ashamed of speaking a foreign language than adolescent learners, and they are prone to anxiety about learning (Brown, 2001). This is inseparable from their social roles. Most of these adult learners have established a certain social image and are always respected. Adult learners often psychologically separate themselves from the outside world, and gradually build an invisible wall to close themselves and form a kind of self-protection. In the process of English learning, even if they don't understand the learning content, they are not willing to expose their defects in order to maintain their self-image, which leads to anxiety and lack of self-confidence. In the classroom, when teachers try to organize some common simulation dialogue or simulation training in language teaching, adult learners are more reserved 
and embarrassed to take part in the language learning activities. As a result, their language abilities in listening, speaking, reading and writing are often unsatisfactory.

\subsection{Adult Learners' Instrumental Motivation in English Learning}

Adult learners usually have their own work, which is busy and stressful. Some students often travel for work, which cannot guarantee the continuity of study time. English is a subject which needs continuous learning and practice, and takes time and effort. If students can't spend a lot of time on English training, it is difficult to achieve satisfactory results. In terms of English learning motivation, because adult learners have a clear learning purpose, they often hope to learn specific content at a specific time, which can be said to be anxious to achieve quick success and get instant benefits. They may adopt the method of studying in a rush before the examination to get a pass in the English examination.

Because adults lack self-confidence and self-awareness in English learning, and the low sense of self-efficacy affects the English learning which needs great efforts. As a teacher engaged in adult English education, it is of great significance to cultivate students' English self-efficacy.

\section{Training Strategies to Improve Adult Learners' English Self-Efficacy}

We need to pay attention to the self-confidence and expectation of adult learners for English learning, that is, to cultivate their sense of self-efficacy, and to educate adults to learn how to study, to make them dare to explore, find the fun of learning and improve their English level. Next, combining the four factors of self-efficacy, this paper explores the ways to cultivate adult learners' English self-efficacy.

\subsection{Past Achievement Experience: Increasing Adult Learners' Successful Experience in English Learning}

Adult learners show a certain degree of self-consciousness and self-control in their study. They have changed their compliance status with teachers and are transforming from passive learning to active learning. However, this kind of autonomous learning is different from general self-learning. The leading role of teachers in teaching and the guidance and suggestions for adult learners' learning are still very important. English self-efficacy is based on the past English learning experience. English teachers should make students go through more successful experience in teaching. For adult learners with low self-efficacy in English learning, it is a feasible way to set lower learning goals for them. For example, English teachers should arrange easy learning tasks for students with poor English foundation, and then give a positive evaluation of their progress. In teaching, teachers can follow the order from simple to difficult. In this way, stu- 
dents can gradually experience their achievements in a relatively simple learning process to improve their confidence in learning.

In addition, the sense of achievement in English learning comes from the successful experience obtained from continuous practice. The continuous successful experience obtained from practice will enable people to establish a stable sense of self-efficacy in English learning, and will not be reduced due to temporary setbacks. Students with low self-confidence often overemphasize the difficulties in learning and overestimate their abilities. Therefore, they should experience and recognize their abilities through continuous successful completion of English learning tasks and solving difficulties in learning practice, and experience success from their own progress. The improvement of self-efficacy is the accumulation of success. It is the key to improve English self-efficacy to let students experience the sense of achievement in practice.

\subsection{Alternative Experience: Providing Positive Role Models and Demonstrations for Adult Learners}

Teachers should provide positive examples and demonstrations for adult learners, and train adults to strengthen themselves actively. In the process of teaching, teachers should often introduce role models to adults, and place certain expectations on adult learners to help them learn to make positive comparison with role models, so as to improve their sense of self-efficacy, which is the effect of self-reinforcement. Research shows that people are not only affected by external reinforcement, but also by self-reinforcement. Self-reinforcement is very important to regulate people's behavior. It is a behavior process that motivates people to reach a certain standard by means of self-reward. In adult English teaching, teachers should first understand the starting point of adult learning through diagnostic tests. On this basis, the new evaluation can make adults find their own progress and improvement. In the process of evaluation, it is necessary to avoid improper comparison between adult learners and other types of students. To guide them to compare their past and present progress in a vertical way will enable them to find their own effectiveness and stimulate their desire for English learning and self-improvement.

In addition, to look at English learning from the perspective of alternative experience, both teachers and learners themselves should analyze the specific problems. In fact, language learning varies from person to person. There are great differences among English learners in terms of cognitive style, age, learning strategies and skills. Therefore, teachers must distinguish different situations when introducing role models. Adults also need to realize the difference between themselves and their role models. Otherwise, it will reduce the self-efficacy of adults to imitate inappropriate role models.

\subsection{Verbal Persuasion: Appropriate Use of Praise and Criticism for Adult Learners}

Verbal persuasion mainly refers to the encouragement and persuasion from the 
society, which requires teachers to discover the progress made by students in time in the teaching process, so as to carry out effective encouragement and praise. The encouragement and praise must also be consistent with the facts, otherwise, it will reduce students' acceptance of teachers' encouragement.

The effect of appropriate praise is obviously better than that of criticism, and the effect of criticism is better than that of no criticism. However, improper use of external rewards will not only lead to negative attribution of adult learners, but also more likely to damage the original intrinsic motivation. Therefore, the praise and reward for adult learners should not only be universal, but also targeted, so that adult learners feel justified, and feel that it is an affirmation of their efforts and abilities. Praise must be aimed at real progress and achievement, and it is given when there is objective evidence that progress and achievement appear directly. It is necessary to explain the reasons of rewards to adult learners. The more rewards, the better. At first, teachers should understand the original learning interests of adult learners, and then consider whether external rewards are necessary.

\subsection{Physiological and Emotional State: Guiding Adult Learners to Make Correct and Reasonable Attribution}

Some adult learners enter the door of adult education because of the failure of college entrance examination. If these students attribute the failure of college entrance examination to their poor ability, their self-efficacy will be reduced. However, if they attribute the failure to their bad luck or insufficient efforts, their self-efficacy will not be greatly affected. Therefore, it is an effective intervention to help students with low learning efficacy to correctly attribute their failure in learning.

Research shows that high emotional arousal and nervous physiological state will hinder the improvement of students' learning and reduce the expected level of success. English teachers should consciously train students in the correct attribution of failure, help them to make English learning plans and implement learning plans. Once students fail in English learning, teachers should analyze the causes of failure from the perspective of task difficulty and effort level together with students in time to help them establish correct attribution habits, so as to help them establish the correct attribution habit. In the process of teaching, English teachers should guide students not to attribute the failure of English learning to their own ability, teach them to evaluate themselves objectively and positively, and make them gradually establish an optimistic learning attitude and a good way of attribution. Teachers should also try to help students to eliminate the negative, anxious and tense emotions in English learning, so as to improve adult learners' English self-efficacy.

\section{Conclusion}

English self-efficacy is a person's self-evaluation of his English ability, which 
shows his confidence in English application. As adult learners lack self-confidence and self-awareness in English learning, the study of adult English self-efficacy and the cultivation of adult English self-efficacy play a positive role in promoting adult learners' English learning ability and interest, which is of great significance for adult learners to learn English.

\section{Acknowledgements}

My thanks to the anonymous reviewers for reading and commenting on the early drafts of this article.

\section{Funding}

The project is supported by the Program on the Exploration and Practice of Multimodal English Teaching Mode for Adult Learners under the Epidemic Situation (Grant No. 2020YQJY552), Special Subject of "Epidemic Situation and Education" of Zhejiang Provincial Education Science Regulated Research in 2020. The Paradigm Establishment of Curriculum Construction in Open University (Grant No. jg20191071), the Second Batch of Teaching Reform Research Projects in "the 13th Five-Year Plan" of Higher Education in Zhejiang Province. Innovation Research Team of English Teaching Paradigm of Zhejiang Open University in 2019.

\section{Conflicts of Interest}

The authors declare no conflicts of interest regarding the publication of this paper.

\section{References}

Atkinson, J. W., \& Feather, N. T. (1980). A Theory of Achievement Motivation (pp. 231-248). New York: John Wiley \& Sons, Inc.

Bandura, A. (1977). Self-Efficacy: Toward a Unifying Theory of Behavioral Change. Psychological Review, 3, 191-215. https://doi.org/10.1037/0033-295X.84.2.191

Bandura, A. (1986). Social Foundation of Thought and Action: A Social Cognitive Theory (pp. 416-417). Englewood Cliffs, NJ: Prentice-Hall, Inc.

Bandura, A. (1995). Self-Efficacy in Changing Societies (pp. 17-23). Cambridge: Cambridge University Press. https://doi.org/10.1017/CBO9780511527692

Brown, H. B. (2001). Teaching by Principles, An Interactive Approach to Language Pedagogy (pp. 69-75). Beijing: Foreign Language Teaching and Research Press.

Chi, L. P., \& Xin, Z. Q. (2006). The Learning Self-Efficacy of Female University Students: Two Evaluated Criteria and Their Harmony. Journal of China Women's University, 5, 20-24.

Li, H. (2017). The Effects of English Writing Self-Efficacy on Non-English Majors' Writing Performance. Foreign Language Learning Theory and Practice, 3, 57-63.

Pajares, F. (1996). Efficacy Beliefs and Mathematical Problem Solving of Gifted Students. Contemporary Educational Psychology, 2, 335-346.

https://doi.org/10.1006/ceps.1996.0025

Zhang, M. Y. (2006). The Relationship Between Academic Self-Efficacy and Achievement 
Motivation of College Students. Journal of Taiyuan University, 2, 61-63.

Zhang, X. M., Yan, X. F., \& Song, H. P. (2017). Improvement of the College Students' English Self-Efficacy from the Perspective of Educational Ecology. Journal of Luliang University, 2, 91-93. 